Journal of Patient-Centered

Volume 2

Issue 3 - Vascular Disease

Article 4

8-14-2015

\title{
Overview of the Role of Duplex Ultrasound for Treatment and Surveillance of Peripheral Arterial Disease
}

John H. Fish III

Peter Klein-Weigel

Gustav Fraedrich

Follow this and additional works at: https://aah.org/jpcrr

Part of the Cardiovascular Diseases Commons, Cardiovascular System Commons, Other Analytical, Diagnostic and Therapeutic Techniques and Equipment Commons, and the Radiology Commons

\section{Recommended Citation}

Fish JH, Klein-Weigel P, Fraedrich G. Overview of the role of duplex ultrasound for treatment and surveillance of peripheral arterial disease. J Patient-Centered Res Rev. 2015;2:104-111. doi:10.17294/ 2330-0698.1056

Published quarterly by Midwest-based health system Advocate Aurora Health and indexed in PubMed Central, the Journal of Patient-Centered Research and Reviews (JPCRR) is an open access, peer-reviewed medical journal focused on disseminating scholarly works devoted to improving patient-centered care practices, health outcomes, and the patient experience. 


\title{
Overview of the Role of Duplex Ultrasound for Treatment and Surveillance of Peripheral Arterial Disease
}

\author{
John H. Fish III, MD, ${ }^{1}$ Peter Klein-Weigel, MD, ${ }^{2}$ Gustav Fraedrich, $\mathrm{MD}^{3}$ \\ ${ }^{1}$ Jobst Vascular Institute, Toledo, $\mathrm{OH}$ \\ ${ }^{2}$ Department of Angiology, HELIOS Clinic Berlin-Buch, Berlin, Germany \\ ${ }^{3}$ Department of Vascular Surgery, University of Innsbruck, Innsbruck, Austria
}

\begin{abstract}
Imaging strategies for preinterventional planning in symptomatic peripheral artery disease have employed various modalities ranging from duplex ultrasound to noninvasive angiography with computed tomography (CT) or magnetic resonance (MRA). These methods have classically been compared to the gold standard of digital subtraction angiography and are reviewed here in detail through the work of relevant published studies and meta-analyses ranging from 1996 to 2014. In particular, we focus on the diagnostic performance, reproducibility and cost-effectiveness of these aforementioned modalities with respect to mapping the lower extremity arterial tree for planning vascular intervention and surveillance. The data presented suggests comparable sensitivity and specificity of duplex ultrasound to contrastenhanced MRA and CT angiography, with the potential for adequate reproducibility given the presence of an accredited vascular lab with highly trained technicians. Cost-effectiveness was shown to be favorable for duplex ultrasound as long as there is diagnostic confidence in the results, which is vital to its success as a viable imaging modality for peripheral artery disease.
\end{abstract}

Keywords vascular imaging, intervention, duplex ultrasound, angiography, magnetic resonance, CT angiography

The diagnosis and staging of peripheral artery disease (PAD) is fundamentally based on medical history and proper clinical examination. ${ }^{1,2}$ Classically, anklebrachial index (ABI), treadmill testing, pulse volume wave recordings and transcutaneous oximetry assist to confirm clinical suspicion and allow for conclusions on the hemodynamic compensation and on the local and systemic prognosis. ${ }^{1}$ In patients with good walking performance without lifestyle limitation, as well as in those not giving informed consent for invasive procedures, there is no need for further vascular imaging except to exclude rare vascular pathologies such as cystic adventitial degeneration, popliteal entrapment syndrome, aneurysm or large-vessel vasculitis. For proper decision-making in symptomatic patients eligible for invasive therapy, more detailed anatomic and functional information of the vascular lesion and inflow and outflow conditions are mandatory.

Correspondence: John H. Fish III, MD, Director of Vascular Medicine, Jobst Vascular Institute, 2109 Hughes Drive,

Suite 450, Toledo, OH, 43606, T: 419-291-2003,

F: 419-479-6977, Email: john.fishmd@promedica.org
Therapeutic decision-making in PAD relies not only on an accurate physical examination but today also requires readily available anatomic and functional information. With the rapid development of new imaging techniques, work-up of patients with PAD prior to endovascular or surgical therapy has become more sophisticated and diverse. ${ }^{1}$ Additionally, enhanced economic pressures force vascular physicians to not only choose the most adequate diagnostic tool for a specific clinical situation, but also to select the most cost-effective option.

Most studies dealing with preinterventional imaging of patients with PAD define the diagnostic accuracy of various imaging methods by comparing the segmental extent and degree of a peripheral stenosis, with digital subtraction angiography (DSA) serving as the gold standard. ${ }^{3,4}$ However, it is interesting to note that higher sensitivities and specificities obtained under these conditions do not necessarily translate into clinical relevance. Different patients with the same degree of luminal narrowing in the same vascular segment might present with different clinical symptoms or might even be free of symptoms, partially due to various 
Table 1. Relative performance of DSA, DUS, CE-MRA, and CTA in peripheral artery disease based on anatomic location, ability to identify wall structures and extramural processes, evaluation of bypass and stents, operator dependence, time to perform and cost issues ${ }^{3-35}$

\begin{tabular}{|c|c|c|c|c|}
\hline & DSA & DUS & CE-MRA & CTA \\
\hline Aorto-iliac disease & ++-+++ & $+-++^{b}$ & +++ & +++ \\
\hline Femoro-popliteal disease & +++ & +++ & +++ & +++ \\
\hline Crural-pedal disease & $++-+++^{a}$ & $++^{\mathrm{c}}$ & $++^{d}$ & ++ \\
\hline Plaque-morphology and wall structure & + & ++-+++ & $+-++^{e}$ & ++ \\
\hline Extramural processes & - & +++ & +++ & +++ \\
\hline $\begin{array}{l}\text { Disturbed by vessel wall or plaque } \\
\text { calcification }\end{array}$ & +-++ & ++-+++ & - & +-++ \\
\hline Examination of stents & ++-+++ & ++-+++ & + & ++ \\
\hline Examination of bypass grafts & +++ & ++-+++ & +++ & +++ \\
\hline Operator dependence & + & ++ & + & + \\
\hline Time consumption & ++ & $++-+++^{f}$ & $++/+++9$ & $++/+++g$ \\
\hline Procedural costs & +++9 & + & ++9 & ++ \\
\hline
\end{tabular}

A "+" denotes least significant contribution and "+++" the highest contribution to the individual parameters relative to the other modalities. A "- "denotes no contribution to the parameter.

CE-MRA, contrast-enhanced magnetic resonance angiography; CTA, computed tomography angiogram; DSA, digital subtraction angiogram; DUS, duplex ultrasound.

a Dependent on selectiveness of contrast media injection and extent of occlusive disease, performance decreases in multilevel disease.

${ }^{b}$ Limited by vessel calcification, bowel gas and obesity.

'Higher for identification of distal crural and pedal target vessels for distal bypass surgery.

${ }^{d}$ Often limited by venous overlay.

e Limited by relatively low spatial resolution.

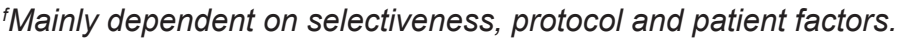

${ }^{g}$ Dependent on selectiveness, protocol and extent of postprocessing.

degrees of muscular remodeling and collateralization. Additionally, blinding study physicians to clinical data - as is usually done in studies comparing different imaging methods to increase scientific objectivity - may actually undermine the clinical effectiveness of a specific diagnostic procedure under "real-life" conditions. In other words, high diagnostic accuracy does not always equate to good clinical usefulness.

Historically, DSA was the method of choice for imaging PAD. Today, preinterventional imaging in PAD can alternatively be performed by contrastenhanced magnetic resonance angiography (CEMRA), contrast-enhanced high-speed multirow computed tomography angiography (CTA) and colorcoded duplex ultrasound (DUS). These imaging modalities distinguish themselves by the strengths and weaknesses summarized in Table 1, which have been described often in the literature. ${ }^{3-35}$
DUS, in particular, offers simultaneous morphological and hemodynamic information as a unique feature. Therefore, the purpose of this overview is to summarize the diagnostic performance and clinical usefulness of DUS compared to DSA, CE-MRA and CTA as primary imaging modalities from a clinical point of view and to describe each modality's ability to guide routine therapeutic decisions in patients with PAD.

A PubMed literature search comprising articles on this topic published in English and German from 1996 to 2014 was supplemented by a manual search of additional relevant papers known to the authors or listed in accompanying reference sections. Literature was then processed according to diagnostic performance, treatment-guiding ability, confidence, reproducibility, surveillance and cost-effectiveness. 
Table 2. Sensitivity and specificity of DUS, CE-MRA and CTA compared to DSA

\begin{tabular}{|c|c|c|c|c|c|c|c|}
\hline \multirow[b]{2}{*}{ Study/meta-analysis } & \multirow[b]{2}{*}{ Inclusion } & \multicolumn{2}{|c|}{ DUS } & \multicolumn{2}{|c|}{ CE-MRA } & \multicolumn{2}{|c|}{ CTA } \\
\hline & & Sensitivity & Specificity & Sensitivity & Specificity & Sensitivity & Specificity \\
\hline Mustapha et al. ${ }^{21}$ & $\begin{array}{c}\text { PAD, mainly } \\
\text { Fontaine stage II }\end{array}$ & $68-82 \%$ & $91-95 \%$ & $78-89 \%$ & $95-98 \%$ & $\mathrm{n} / \mathrm{a}$ & $\mathrm{n} / \mathrm{a}$ \\
\hline Langer et al. ${ }^{18}$ & $\begin{array}{l}\text { PAD, Fontaine } \\
\text { stage II }\end{array}$ & $72 \%$ & $97 \%$ & $81 \%$ & $92 \%$ & $\mathrm{n} / \mathrm{a}$ & $\mathrm{n} / \mathrm{a}$ \\
\hline Ihlberg et al. ${ }^{13}$ & $\begin{array}{c}\text { PAD, mainly } \\
\text { Fontaine stage II }\end{array}$ & 80-86\% & $97 \%$ & $\mathrm{n} / \mathrm{a}$ & $\mathrm{n} / \mathrm{a}$ & $\mathrm{n} / \mathrm{a}$ & $\mathrm{n} / \mathrm{a}$ \\
\hline Collins et al. ${ }^{8}$ & $\begin{array}{l}\text { PAD, mainly } \\
\text { Fontaine stage IV }\end{array}$ & 85-93\% & $71-86 \%$ & $\mathrm{n} / \mathrm{a}$ & $\mathrm{n} / \mathrm{a}$ & $\mathrm{n} / \mathrm{a}$ & $\mathrm{n} / \mathrm{a}$ \\
\hline Ascher et al. ${ }^{7}$ & $\begin{array}{c}\text { PAD, mainly } \\
\text { Fontaine stage II }\end{array}$ & 80-98\% & 89-99\% & $92-99.5 \%$ & 64-99\% & 89-99\% & 83-97\% \\
\hline Meissner et al. ${ }^{20}$ & $\begin{array}{l}\text { PAD, Rutherford } \\
\text { class } \geq 111\end{array}$ & $\begin{array}{l}93 \% \\
\text { (crural) }\end{array}$ & $\begin{array}{l}40 \% \\
\text { (crural) }\end{array}$ & $\mathrm{n} / \mathrm{a}$ & $n / a$ & $\mathrm{n} / \mathrm{a}$ & $\mathrm{n} / \mathrm{a}$ \\
\hline
\end{tabular}

DUS, duplex ultrasound; CE-MRA, contrast-enhanced magnetic resonance angiography; CTA, computed tomography angiogram; $D S A$, digital subtraction angiogram; $n / a=$ not applicable; $P A D$, peripheral artery disease.

\section{Diagnostic Performance of DUS, CE-MRA and CTA vs. DSA}

There are several published meta-analyses comparing DUS, CE-MRA and CTA with DSA, which include up to 113 relevant studies. ${ }^{8,17,19,21,22}$ Results are presented in Table 2. The data do not include DUS studies addressing postexercise Doppler spectral analysis, which might increase sensitivity in the case of iliac pathology, ${ }^{23}$ nor does it reflect recent developments in imaging technologies, including emerging ultrasound modalities like contrast-enhanced ultrasound. However, the reported sensitivities and specificities are comparable to more recently published data for CEMRA and CTA obtained with modern hardware and software modalities. ${ }^{3,4}$

The performance of DUS in the infrapopliteal runoff via the crural (tibial/peroneal arteries) and pedal vessels compared to DSA was analyzed separately in five selected citations. ${ }^{11,12,16,18,21}$ This was most recently studied by the Joint Endovascular and Non-Invasive Assessment of LImb perfusion (JENALI) Group, which used a novel anatomical scoring system to compare its ability to detect patent or occluded vessels compared to DSA. ${ }^{21}$ The highest accuracy was in the (more superficial) tibial arteries compared to the peroneal artery; data are summarized in Table 2.

\section{Ability of DUS in Defining Treatment Plans}

From a practical standpoint, DUS - although inferior to CE-MRA and CTA in the aforementioned studies in terms of sensitivity and specificity - was found to be as good as DSA in designing the final treatment plan for patients with PAD. ${ }^{8,14}$ These findings are in agreement with older data from Aly et al. and Elsman et al., who reported that treatment strategies in PAD can be determined safely on the results of DUS alone, since preinterventional DSA did not provide any additional diagnostic benefit in their studies. ${ }^{6,10}$ Ascher et al. reported positive experiences with DUS for preoperative evaluation in 466 patients who were ultimately scheduled for 485 lower extremity revascularization procedures. Only a small number of patients $(7 \%)$ required additional preoperative imaging procedures for planning final treatment. ${ }^{7}$ DUS also was reported to allow selective use of arteriography in the management of patients with severe PAD. ${ }^{16}$ High-quality DUS performed by well-trained vascular technologists or physicians may therefore represent a good alternative for patients in need of lower extremity revascularization even in cases of more complex and critical disease. This was supported by Grassbaugh et al., who compared preoperative DUS with DSA for planning of revascularization at the crural (tibial/ peroneal arterial) level ${ }^{11}$ as well as more recently by 
Table 3. Coefficients of peak systolic velocity values in duplex ultrasound

\begin{tabular}{|c|c|c|c|c|c|c|}
\hline \multirow[b]{2}{*}{ Location of stenosis } & \multicolumn{2}{|c|}{ Koelemay et al. ${ }^{14}$} & \multicolumn{2}{|c|}{ Schäberle et al..$^{23}$} & \multicolumn{2}{|c|}{ Collins et al. ${ }^{8}$} \\
\hline & $\begin{array}{l}\text { popliteo- } \\
\text { crural }\end{array}$ & pedal & aorto-iliac & $\begin{array}{l}\text { femoro- } \\
\text { popliteal }\end{array}$ & $\begin{array}{l}\text { femoro- } \\
\text { popliteal }\end{array}$ & pedal \\
\hline Intraclass correlation coefficient & 0.90 & 0.64 & 0.72 & 0.85 & $\mathrm{n} / \mathrm{c}$ & $n / c$ \\
\hline Kappa coefficient & 0.66 & 0.54 & 0.53 & 0.73 & 0.84 & 0.61 \\
\hline
\end{tabular}

$n / c$, not calculated.

Wong et al., who found DUS to be accurate enough to guide initial clinical management of patients with PAD. ${ }^{31}$

\section{Confidence in DUS}

Replacing familiar diagnostic methods with newer imaging modalities and paradigms has led to some uneasiness among the international vascular community. ${ }^{5,25,26,28}$ For example, Visser and Hunink reviewed the impact of replacing DUS with CE-MRA for the initial imaging work-up of patients with PAD. ${ }^{26}$ In their meta-analysis, DUS was graded with lower confidence scores compared to MRA among vascular surgeons and led to more repeat imaging, although total imaging costs were significantly lower with DUS. Outcomes of surgical intervention were judged to be similar. The lower confidence in DUS may have been influenced by operational bias and surgeons who were not comfortable with the routine use of DUS. Similar results were published recently by an American-Dutch cooperative project in which imaging data from 12 patients with PAD were independently reviewed by two American vascular surgeons and one Dutch vascular surgeon. PAD treatment planning based on CTA was mostly consistent with DUS-based treatment plans, although additional CTA in the DUS group was determined to be necessary to increase confidence. These observations suggest that in order to promote greater use of the less costly DUS imaging, improvement in clinician confidence is required. ${ }^{28}$

\section{Reproducibility of DUS}

Reliability of DUS in therapeutic decision-making requires high interobserver agreement. While the studies related to this topic (summarized in Table 3 ) all argue against the belief that DUS is highly subjective and poorly reproducible in all scenarios, ${ }^{9,15,24}$ there was only moderate correlation in the iliac and pedal areas. For the pedal arteries, this was theorized to be the result of very small vessels that, because of their superficial location in the foot, can be easily compressed with the transducer, in addition to possible detection of flow in collateral arteries mistaken for the native vessel. In the iliac region, bowel gas and the deep location of the arteries were cited as reasons for variability in correlation, although the results of Ubbink and colleagues showed otherwise good correlation that was only slightly inferior to the femoral-popliteal segment. ${ }^{24}$ The relevance of increased interobserver variance with systolic velocity ratios in symptomatic patients, thereby causing variable degrees of stenosis, is tempered by the fact that establishing the hemodynamic relevance of a stenosis is much more important for clinical decision-making in such patients than the exact quantification of stenosis. In other words, once a stenotic lesion has been identified to be clinically and hemodynamically relevant, the numerical degree of stenosis is of secondary importance.

In addition to the interobserver variability in arterial DUS (kappa 0.53-0.84, Table 3), interobserver variability in interpretation has been described for DSA, MRA and CTA as well. In the study by Eiberg et al. addressing the operator dependency of DUS and DSA, DUS was comparable to DSA in chronic limb ischemia. The interobserver agreement for DSA, expressed as kappa values, was 0.80 (95\% confidence interval [CI]: 0.74-0.87) for the limb as a whole. Statistically significant differences in individual segments were not detected. ${ }^{8}$ Good interobserver agreement for MRA, as recently measured against DSA, had a kappa ranging from 0.74 to 0.86 , with the infrapopliteal segments showing the lowest agreement. ${ }^{32,33}$ Finally, a report grading interobserver agreement for CTA found kappa 
values of $0.79 \pm 0.08$ (95\% CI: $0.78-0.80)$ in arterial lesions above the knee and $0.78 \pm 0.03$ (95\% CI: $0.77-$ $0.78)$ in the below-knee group, ${ }^{34}$ similar to results reported by Catalano et al. for all segments $(0.812)$ and for the popliteal and infrapopliteal arteries $(0.774) .{ }^{35}$

\section{Performance of DUS in Peripheral Bypass Surveillance and in Identification of Distal Bypass Target Vessels}

Studies on the precision of DUS in peripheral bypass surveillance yielded conflicting results. Ihlberg et al. praised DUS to be an accurate and reproducible method for detecting hemodynamically significant changes in infrainguinal vein grafts. ${ }^{13}$ Meissner et al. reported concordant findings in 109 of 117 segments in 24 consecutive patients with 26 grafts following infrapopliteal bypass. $^{20}$ In the eight discordant segments, DUS overlooked four high-grade bypass stenoses correctly identified by MRA and consecutively treated by percutaneous transluminal angioplasty. Nevertheless, the absolute number of grafts included in this study was low, limiting statistical power. In another study by Willmann et al., there was both excellent agreement between different readers and between CTA and DUS in the detection of graft stenoses and other vascular complications such as aneurysms or arteriovenous fistulas after peripheral bypass surgery. Compared with DSA and CTA, DUS showed no statistically significant differences in the detection of clinically relevant bypass pathologies. ${ }^{30}$

Crural (tibial/peroneal) percutaneous transluminal angioplasty and bypass grafting to distal infrapopliteal and pedal vessels have been established as effective limb salvage procedures in critical limb ischemia. Identification of patent distal target vessels is critical in these patients. As shown by Grassbaugh et al., target vessel selection for operative procedures was reliable with DUS. ${ }^{11}$ With the use of high-frequency ultrasound probes, Hofmann et al. identified significantly more distal target segments with DUS compared to DSA and CE-MRA. ${ }^{12}$ On the other hand, Langer et al. identified significantly more patent pedal arteries by 3-Tesla high-resolution three-dimensional CE-MRA compared with DSA or DUS, suggesting that performance of a diagnostic modality highly depends on technical advance, procedural modifications and the protocol used. ${ }^{18}$

\section{Cost-Effectiveness of DUS}

Cost analysis for the preinterventional imaging of intermittent claudication based on decision-analysis models found only slight differences in costs and effectiveness among the different diagnostic imaging strategies with some advantages for DUS and CEMRA, ${ }^{27}$ whereas in the meta-analysis by Collins et al., a clear cost advantage for DUS over all other imaging methods was calculated. ${ }^{8}$ When the whole leg was assessed by a preprocedural diagnostic test, DUS dominated all other alternatives by presenting higher effectiveness at a lower cost per quality-adjusted lifeyear. ${ }^{8}$

Interestingly, confidence also seems to play a major role in economic consequences of preinterventional imaging. As shown by de Vries et al., the use of CEMRA was associated with higher costs than DUS but reduced the number of additional vascular imaging procedures by $42 \%$ as the former was associated with higher therapeutic confidence. Thus, due to low confidence in DUS, no statistically significant differences were found for total cost in their study. ${ }^{29}$

\section{Clinical Decision-Making}

With the emerging technical progress in DUS, CE-MRA and CTA, choosing an imaging modality for PAD has become more sophisticated and challenging. Given its invasiveness, complication rates, costs and relatively high radiation dose, DSA now should be limited to therapeutic interventions. ${ }^{1}$ Due to its high spatial resolution, DSA might be indicated diagnostically to visualize acral vascular beds if this information is considered relevant for differential diagnosis and/or therapeutic decision-making.

DUS simultaneously provides morphologic and hemodynamic information. Although CE-MRA and CTA can accurately image the vascular tree and guide clinical decisions, their routine availability and clinical application may be limited. They are also qualitatively diverse, more costly and much more complex when compared to DUS. Despite these shortcomings and limitations, CE-MRA and CTA are alternatives to DUS in the case of a nondiagnostic DUS or when a more complete overview of the vascular tree is needed, such as with patients with multilevel disease destined for complex invasive interventions. 
A general problem in many papers addressing the diagnostic performance of imaging methods is that they often do not distinguish intermittent claudication from critical limb ischemia (CLI) or chronic from acute disease, although these categories represent different patients with different clinical outcomes and different segmental manifestations. The evaluation of noninvasive imaging modalities has predominantly been based on patients with intermittent claudication. ${ }^{8}$ One may presume, however, that diagnostic tools perform differently in patients with CLI who have more extensive disease. Nevertheless, in a recently published meta-analysis of CTA and CE-MRA in patients with CLI and intermittent claudication, the authors did not identify CLI as an independent predictor of diagnostic performance. ${ }^{4}$ Whether this is also true for DUS was not addressed.

For preinterventional assessment of the vascular status in cases complicated by aneurysms or for instent lesions, DUS and CTA have advantages over CE-MRA. According to limited published data, CEMRA and CTA are not superior to DUS in evaluating peripheral bypass grafts. ${ }^{13,30}$ Thus, from both a practical and economic point of view, it seems reasonable to use DUS routinely for peripheral bypass surveillance.

Although CE-MRA and CTA may be enticing with their impressive images, clinical decision-making in the majority of PAD patients can be accurately, safely and cost-effectively navigated through proper basic clinical examination and DUS. Bias against DUS is based on low confidence (shown to be prevalent among some groups of vascular surgeons) due to a lack of experience with this method and the fact that maximum intensity projections in CE-MRA and CTA resemble conventional angiograms but are prone to artifact. Legal concerns to ground a therapeutic decision on a method that is unable to document images of the whole vascular tree are without substance since vascular ultrasound documentation standards have been developed by international accrediting organizations such as the Intersocietal Accreditation Commission (North America), German Society for Ultrasound in Medicine (DEGUM), Austrian Society for Ultrasound in Medicine (ÖGUM) and Swiss Society for Ultrasound in Medicine (SGUM).

\section{Conclusions}

Gaining confidence in DUS is vital to its success as a viable imaging modality for peripheral artery disease. This can be achieved through proper training and expertise. The incorporation of vascular ultrasound training into the curricula of vascular specialists, interdisciplinary initiatives provided by ultrasound academies, and the participation of various vascular specialists in working groups on vascular ultrasound are hopeful signs of change to simplify and reduce costs of preinterventional imaging of PAD.

\section{Patient-Friendly Recap}

- Several imaging tools are available for mapping arteries in the legs and feet.

- Of these, duplex ultrasound is the most costeffective, but clinicians lack confidence in its ability to precisely diagnose peripheral artery disease.

- Based on the authors' review of published reports, duplex ultrasound provides similar results to other more costly imaging tools, especially when used by highly trained technicians.

- Duplex ultrasound may be underused in planning treatment for peripheral artery disease.

\section{Conflicts of Interest}

None.

\section{REFERENCES}

1. Hirsch AT, Haskal ZJ, Hertzer NR, et al. ACC/AHA 2005 Practice Guidelines for the management of patients with peripheral arterial disease (lower extremity, renal, mesenteric, and abdominal aortic): a collaborative report from the American Association for Vascular Surgery/Society for Vascular Surgery, Society for Cardiovascular Angiography and Interventions, Society for Vascular Medicine and Biology, Society of Interventional Radiology, and the ACC/AHA Task Force on Practice Guidelines (Writing Committee to Develop Guidelines for the Management of Patients With Peripheral Arterial Disease): endorsed by the American Association of Cardiovascular and Pulmonary Rehabilitation; National Heart, Lung, and Blood Institute; Society for Vascular Nursing; TransAtlantic Inter-Society Consensus; and Vascular Disease Foundation. Circulation. 2006;113:e463-654. CrossRef

2. European Stroke Organisation, Tendera M, Aboyans V, et al. ESC Guidelines on the diagnosis and treatment of peripheral artery diseases: Document covering atherosclerotic disease of extracranial carotid and vertebral, mesenteric, renal, upper 
and lower extremity arteries: the Task Force on the Diagnosis and Treatment of Peripheral Artery Diseases of the European Society of Cardiology (ESC). Eur Heart J. 2011;32:2851-906. CrossRef

3. Duan Y, Wang X, Yang X, Wu D, Cheng Z, Wu L. Diagnostic efficiency of low-dose CT angiography compared with conventional angiography in peripheral arterial occlusions. Am J Roentgenol. 2013;201:W906-14. CrossRef

4. Jens S, Koelemay MJ, Reekers JA, Bipat S. Diagnostic performance of computed tomography angiography and contrast-enhanced magnetic resonance angiography in patients with critical limb ischaemia and intermittent claudication: systematic review and meta-analysis. Eur Radiol. 2013;23:3104-14. CrossRef

5. Adriaensen ME, Kock MC, Stijnen $T$, et al. Peripheral arterial disease: therapeutic confidence of CT versus digital subtraction angiography and effects on additional imaging recommendations. Radiology. 2004;233:385-91. CrossRef

6. Aly S, Shoab S, Bishop C. Inter-observer variation. An alternative method of assessing the role of ultrasonic imaging in clinical decision-making in lower limb arterial disease. Int Angiol. 1999;18:220-4.

7. Ascher E, Hingorani A, Markevich N, Costa T, Kallakuri S, Khanimoy Y. Lower extremity revascularization without preoperative contrast arteriography: experience with duplex ultrasound arterial mapping in 485 cases. Ann Vasc Surg. 2002;16:108-14. CrossRef

8. Collins R, Burch J, Cranny G, et al. Duplex ultrasonography, magnetic resonance angiography, and computed tomography angiography for diagnosis and assessment of symptomatic, lower limb peripheral arterial disease: systematic review. BMJ. 2007;334:1257. CrossRef

9. Eiberg JP, Madycki G, Hansen MA, Christiansen S, Grønvall Rasmussen JB, Schroeder TV. Ultrasound imaging of infrainguinal arterial disease has a high interobserver agreement. Eur J Vasc Endovasc Surg. 2002;24:293-9. CrossRef

10. Elsman BH, Legemate DA, van der Heijden FH, de Vos HJ, Mali WP, Eikelboom BC. Impact of ultrasonographic duplex scanning on therapeutic decision making in lower-limb arterial disease. Br J Surg. 1995;82:630-3. CrossRef

11. Grassbaugh JA, Nelson PR, Rzucidlo EM, et al. Blinded comparison of preoperative duplex ultrasound scanning and contrast arteriography for planning revascularization at the level of the tibia. J Vasc Surg. 2003;37:1186-90. CrossRef

12. Hofmann WJ, Walter J, Ugurluoglu A, Czerny M, Forstner R, Magometschnigg H. Preoperative high-frequency duplex scanning of potential pedal target vessels. J Vasc Surg. 2004;39:169-75. CrossRef

13. Ihlberg L, Albäck A, Roth WD, Edgren J, Lepäntalo M. Interobserver agreement in duplex scanning for vein grafts. Eur J Vasc Endovasc Surg. 2000;19:504-8. CrossRef

14. Koelemay MJ, den Hartog D, Prins MH, Kromhout JG, Legemate DA, Jacobs MJ. Diagnosis of arterial disease of the lower extremities with duplex ultrasonography. Br J Surg. 1996;83:404-9. CrossRef

15. Koelemay MJ, Legemate DA, van Gurp JA, de Vos H, Balm R, Jacobs MJ. Interobserver variation of colour duplex scanning of the popliteal, tibial and pedal arteries. Eur J Vasc Endovasc Surg. 2001;21:160-4. CrossRef

16. Koelemay MJ, Legemate DA, de Vos H, et al. Duplex scanning allows selective use of arteriography in the management of patients with severe lower leg arterial disease. J Vasc Surg. 2001;34:661-7. CrossRef

17. Koelemay MJ, Lijmer JG, Stoker J, Legemate DA, Bossuyt PM. Magnetic resonance angiography for the evaluation of lower extremity arterial disease: a meta-analysis. JAMA. 2001;285:1338-45. CrossRef

18. Langer S, Krämer N, Mommertz G, et al. Unmasking pedal arteries in patients with critical ischemia using time-resolved contrast-enhanced 3D MRA. J Vasc Surg. 2009;49:1196-202. CrossRef

19. Lundin P, Svensson A, Henriksen E, et al. Imaging of aortoiliac arterial disease. Duplex ultrasound and MR angiography versus digital subtraction angiography. Acta Radiol. 2000;41:125-32. CrossRef

20. Meissner OA, Verrel F, Tató F, et al. Magnetic resonance angiography in the follow-up of distal lower-extremity bypass surgery: comparison with duplex ultrasound and digital subtraction angiography. J Vasc Interv Radiol. 2004;15:126977. CrossRef

21. Mustapha JA, Saab F, Diaz-Sandoval L, et al. Comparison between angiographic and arterial duplex ultrasound assessment of tibial arteries in patients with peripheral arterial disease: on behalf of the Joint Endovascular and Non-Invasive Assessment of LImb Perfusion (JENALI) Group. J Invasive Cardiol. 2013;25:606-11.

22. Nelemans PJ, Leiner T, de Vet HC, van Engelshoven JM. Peripheral arterial disease: meta-analysis of the diagnostic performance of MR angiography. Radiology. 2000;217:10514. CrossRef

23. Schäberle W, Rupp-Heim G, Leyerer L. Duplexsonographische Diagnostik von Beckenarterienstenosen. Stenosegraduierung und zeiteffizientes Vorgehen durch Spektralanalyse. Gefaesschirurgie. 2013;18:44-51.

24. Ubbink DT, Fidler M, Legemate DA. Interobserver variability in aortoiliac and femoropopliteal duplex scanning. J Vasc Surg. 2001;33:540-5. $\underline{\text { CrossRef }}$

25. Vavrik J, Rohrmoser GM, Madani B, Ersek M, Tscholakoff D, Bucek RA. Comparison of MR angiography versus digital subtraction angiography as a basis for planning treatment of lower limb occlusive disease. J Endovasc Ther. 2004;11:294301. CrossRef

26. Visser K, Hunink MG. Peripheral arterial disease: gadoliniumenhanced MR angiography versus color-guided duplex US--a meta-analysis. Radiology. 2000;216:67-77. CrossRef

27. Visser K, Kuntz KM, Donaldson MC, Gazelle GS, Hunink MG. Pretreatment imaging workup for patients with intermittent claudication: a cost-effectiveness analysis. $J$ Vasc Interv Radiol. 2003;14:53-62.

28. de Vos MS, Bol BJ, Gravereaux EC, Hamming JF, Nguyen LL. Treatment planning for peripheral arterial disease based on duplex ultrasonography and computed tomography angiography: consistency, confidence and the value of additional imaging. Surgery. 2014;156:492-502. CrossRef

29. de Vries M, Ouwendijk R, Flobbe K, et al. Peripheral arterial disease: clinical and cost comparisons between duplex US and contrast-enhanced MR angiography--a multicenter randomized trial. Radiology. 2006;240:401-10. CrossRef

30. Willmann JK, Mayer D, Banyai M, et al. Evaluation of peripheral arterial bypass grafts with multi-detector row CT angiography: comparison with duplex US and digital 
subtraction angiography. Radiology. 2003;229:465-74. CrossRef

31. Wong TH, Tay KH, Sebastian MG, Tan SG. Duplex ultrasonography arteriography as first-line investigation for peripheral vascular disease. Singapore Med J. 2013;54:271-4. CrossRef

32. Wang CC, Liang HL, Hsiao CC, et al. Single-dose timeresolved contract enhanced hybrid MR angiography in diagnosis of peripheral arterial disease: compared with digital subtraction angiography. J Magn Reson Imaging. 2010;32:935-42. CrossRef

33. Grijalba FU, Esandi MC. Comparison of gadofosvesetenhanced three-dimensional magnetic resonance angiography with digital subtraction angiography for lower-extremity peripheral arterial occlusive disease. Acta Radiol. 2010;51:284-9. CrossRef

34. Bui TD, Gelfand D, Whipple S, et al. Comparison of CT and catheter arteriography for evaluation of peripheral arterial disease. Vasc Endovasc Surg. 2005;39:481-90. CrossRef

35. Catalano C, Fraioli F, Laghi A, et al. Infrarenal aortic and lower-extremity arterial disease: diagnostic performance of multi-detector row CT angiography. Radiology. 2004;231:55563. CrossRef

(C) 2015 Aurora Health Care, Inc. 